\title{
Attending, ignoring, and repetition: On the relation between negative priming and inhibition of return
}

\author{
BRUCE MILLIKEN \\ McMaster University, Hamilton, Ontario, Cunada \\ STEVEN P. TIPPER \\ University of Wales, Bangor, Wales \\ GEORGE HOUGHTON \\ University College, London, England \\ and \\ JUAN LUPIÁÑEZ \\ Universidad de Granada, Granada, Spain
}

\begin{abstract}
A series of spatial localization experiments is reported that addresses the relation between negative priming and inhibition of return. The results of Experiment 1 demonstrate that slowed responses to repeated location stimuli can be obscured by repetition priming effects involving stimulus dimensions other than spatial location. The results of Experiments 2, 3A, and 3B demonstrate that these repetition priming effects may occur only when participants are required to respond to the prime display. Together, these results suggest that differences between attended and ignored repetition effects in selective attention studies of spatial localization do not provide a basis for distinguishing between spatial negative priming and inhibition of return.
\end{abstract}

Repeating an action often increases its efficiency. The benefit of repetition is obvious in the learning of new skills but also can be observed under experimental conditions that tap highly practiced skills, such as word identification (Jacoby \& Dallas, 1981; Scarborough, Cortese, \& Scarborough, 1977). The term repetition priming is often used to describe the wide array of such effects that have been observed in the laboratory.

Because practicing a complex behavior so reliably results in learning and because repetition benefits are so commonly observed in the laboratory, researchers have made special note of each of a variety of experimental conditions that produce the opposite result. This article focuses on the relation between two empirical phenomena that measure repetition costs: negative priming (Tipper, 1985) and inhibition of return (Posner \& Cohen, 1984). The proposal forwarded in this article is that negative priming and inhibition of return may be determined by the

This research was supported by a Natural Science and Engineering Research Council of Canada (NSERC) postdoctoral fellowship and research grants awarded to B.M. and by an NSERC research grant awarded to S.P.T. We thank Tram Neill, John Christie, and four anonymous reviewers for comments on earlier versions of this article. Correspondence concerning this article should be addressed to B. Milliken, Department of Psychology, McMaster University, Hamilton, ON L8S 4K1 Canada (e-mail: millike@mcmaster.ca). same cause but are often attributed to different causes for reasons related to experimental procedure. Specifically, negative priming is commonly measured with a procedure in which the participant attends to a target and ignores a distractor in two consecutive displays. Consequently, negative priming is thought to reflect a process that is engaged specifically to solve a selective attention problem. By contrast, inhibition of return is not measured with a selective attention procedure. If negative priming measures a process that is related specifically to selective attention, inhibition of return cannot possibly measure the same process(es).

On the other hand, if negative priming is not caused by processes that are specific to selective attention tasks, inhibition of return and negative priming could conceivably measure the same process(es). Indeed, the experiments reported here demonstrate that negative priming in spatial localization tasks does not depend on selective attention task demands. Furthermore, the results suggest that selective attention demands in a negative priming task can produce an effect that masks an underlying similarity between negative priming and inhibition of return. The theoretical implications of these results are addressed in the General Discussion section. The remainder of the introduction sets the research in context by providing brief reviews of the negative priming and inhibition of return literatures. 


\section{PRIME}

Attended Repetition

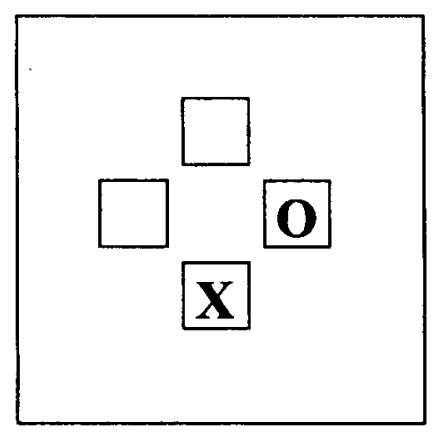

\section{Ignored Repetition}

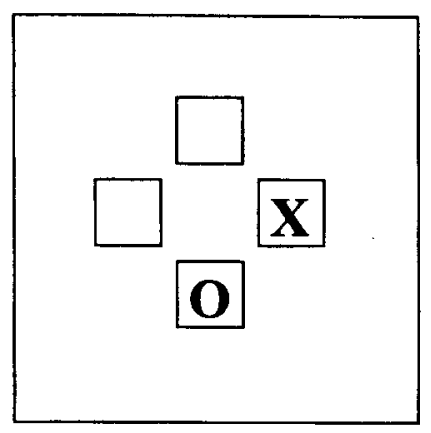

\section{PROBE}

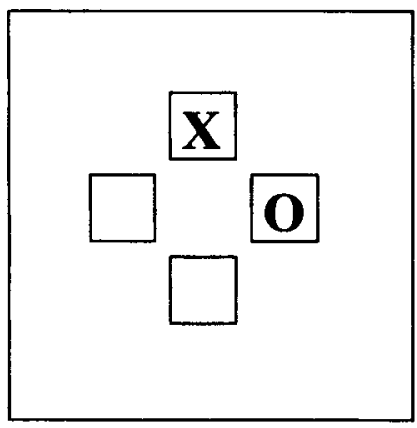

Figure 1. An adaptation of the spatial localization paradigm used by Tipper, Brehaut, and Driver (1990). Participants are asked to localize the $O$ and ignore the location of the $X$. In the ignored repetition condition, the location of the $O$ in the probe display is the same as that of the $X$ in the prime display. In the control condition, both the $O$ and the $X$ appear in locations that were unoccupied in the prime display. In the attended repetition condition, the location of the $O$ is the same in both the prime and the probe displays.

\section{NEGATIVE PRIMING}

An adaptation of the spatial localization variant of the negative priming procedure introduced by Tipper, Brehaut, and Driver (1990) is presented in Figure 1 (see Fox, 1995, May, Kane, \& Hasher, 1995, and Neill, Valdes, \& Terry, 1995, for reviews of the wider literature on negative priming). In this task, the participants are asked to respond by locating a target stimulus, first in a prime display, and then again in a probe display. In both displays, four marked locations appear, one of which is occupied by the symbol $\mathrm{O}$, and a second which is occupied by the symbol $\mathrm{X}$. Responses are made by pressing a key that is spatially compatible with the location of the $O$ in both displays. A critical result in such studies is that response times (RTs) are slower when the probe target $O$ appears in the same location as the prime distractor $\mathrm{X}$ than when it appears in a previously unoccupied location.

According to the distractor inhibition hypothesis, this negative priming effect (henceforth referred to as spatial negative priming) occurs because the location of the prime distractor $\mathrm{X}$ is inhibited in order to allow efficient selection and response to the location of the prime target $\mathrm{O}$. By contrast, attended repetition trials might be expected to benefit from the attention afforded to the prime target, resulting in a facilitory priming effect. In fact, studies that have used this procedure have consistently produced negative priming for ignored repetitions but have less consistently produced positive priming for attended repetitions. Some studies have revealed attended repetition benefits (Park \& Kanwisher, 1994; Tipper et al., 1990), and others have revealed attended repetition costs (Shapiro \& Loughlin, 1993). The occasional finding of RT costs for targets at previously attended locations has prompted researchers to speculate that inhibition of return, an effect commonly observed in attentional cuing studies (Shapiro \& Loughlin, 1993; Tipper et al., 1990), may also occur in selective attention studies. However, the more interesting possibility, that spatial negative priming and inhibition of return reflect the same underlying processes, has been discussed much less frequently. Indeed, if the published articles on these two phenomena 
are any indication, the literature currently treats them as tapping different underlying processes (but see Houghton \& Tipper, 1994).

\section{INHIBITION OF RETURN}

Posner and Cohen (1984) demonstrated that participants are often slower to detect a target at a previously cued location than at a previously uncued location. In the procedure used by Posner and Cohen, participants were required to detect a target that appeared with high probability (.6) at a central location and with low probability (.1) at either of two peripheral locations. On the remaining trials, no target was displayed. Prior to the onset of the target, one of the two peripheral locations was cued by abruptly increasing the luminance of the marker for that location. Onset of the target occurred at varying stimulus onset asynchronies (SOAs) following the cue.

When onset of the cue was followed $100 \mathrm{msec}$ later by onset of the target, detection times were faster at the cued location than at the uncued location. However, when the interval between cue onset and target onset was $300 \mathrm{msec}$ or greater, detection times were reliably slower at the cued location than at the uncued location. Posner and Cohen (1984) suggested that this latter effect results from a bias against returning attention to a previously attended location, an explanation that led researchers to refer to the effect as inhibition of return (Posner, Rafal, Choate, \& Vaughan, 1985).

Inhibition of return has now been observed with a wide array of experimental procedures, including visual target localization (Maylor, 1985), report of the onset of auditory targets (e.g., Mondor, Breau, \& Milliken, 1998; Reuter-Lorenz, Jha, \& Rosenquist, 1996), eye movements to a cued location (e.g., Abrams \& Dobkin, 1994), discrimination of targets from nontargets (e.g., Lupiáñez, Milán, Tornay, Madrid, \& Tudela, 1997; Pratt, 1995; but see Terry, Valdes, \& Neill, 1994), and temporal order judgments (Gibson \& Egeth, 1994). Given the robustness of this effect, it seems plausible that the processes that cause inhibition of return could also operate in the context of a selective attention task (Shapiro \& Loughlin, 1993). The objective of the present research is not only to examine the occurrence of inhibition of return in selective attention tasks, but also to evaluate whether spatial negative priming and inhibition of return have the same cause.

\section{PROCEDURAL VERSUS PROCESS DISTINCTIONS}

In the experiments reported below, we take advantage of the fact that target localization tasks have been used to measure both inhibition of return and spatial negative priming (e.g., Maylor, 1985; Posner, Cohen, Choate, Hockey, \& Maylor, 1984; Shapiro \& Loughlin, 1993; Tipper et al., 1990). Spatial negative priming effects are usu- ally measured by requiring participants to locate a target letter and ignore a distractor letter in consecutive displays. In contrast, inhibition of return effects are often measured by requiring participants to detect or locate a target stimulus that follows either an exogenous attentional cue (Posner \& Cohen, 1984; Rafal, Calabresi, Brennan, \& Sciolto, 1989; Tipper, Driver, \& Weaver, 1991) or a single target item in a previous display (Maylor, 1985). As such, the procedures used to measure negative priming and inhibition of return can be distinguished from one another easily enough. Our objective is to determine whether these differences in procedure require that negative priming and inhibition of return be attributed to different processes.

Given conventional theoretical accounts of these phenomena (e.g., Posner \& Cohen, 1984; Tipper et al., 1990), an important distinction is that negative priming reflects slowed processing for a target in a previously ignored location, whereas inhibition of return reflects slowed processing for a target in a previously attended location. Furthermore, selective attention procedures used to measure negative priming often reveal slowed responding for previously ignored locations, but not for previously attended locations (e.g., Tipper et al., 1990). This result may be taken to imply that an attentional process that suppresses distractors is operative in selective attention tasks but that an attentional process that prevents attention from returning to previously attended locations is not operative in selective attention tasks. Counter to this view, the experiments reported here demonstrate that priming effects involving attended stimulus dimensions other than spatial location can obscure an underlying similarity between inhibition of return and spatial negative priming effects.

The experiments reported here were simple in design. In Experiment 1, the participants responded selectively to the location of a target and ignored the location of a distractor in two consecutive displays. The results of this experiment demonstrate that repeating the color used to select a target produces a facilitory priming effect that masks an underlying slowing of response to repeated location targets. In Experiment 2, the participants were shown the same type of displays but were asked to respond to a target stimulus only in the second of two displays. This procedure eliminated the color repetition effect that obscured the slowing of response to repeated location targets in Experiment 1, thus revealing uniformly slowed responses to any probe target that appeared in a previously occupied prime location. In the final two experiments, a single prime stimulus was followed by either a single probe (Experiment $3 \mathrm{~A}$ ) or a probe target and distractor (Experiment 3B). The results of these two experiments were nearly identical, confirming that adding a discrimination component to the task used here does not eliminate the slowing of response to repeated location targets. Together, the results demonstrate that RT costs for repeated location targets are robust across many variants of the spatial localization task and, in particular, that they can occur both 
for previously attended and previously ignored locations in selective attention tasks. Consequently, we conclude that spatial negative priming and inhibition of return may have a common cause.

\section{EXPERIMENT 1}

The procedure used in many spatial negative priming studies requires participants to respond to the location of a target symbol (e.g., an $\mathrm{O}$ ) while ignoring the location of a distractor symbol (e.g., an X) in consecutive displays. Differences between priming effects for targets in previously attended and previously ignored locations have then been used to distinguish between spatial negative priming and inhibition of return (Tipper et al., 1990). However, a problem inherent to comparing attended and ignored repetition effects with this procedure is that attended repetition trials differ from ignored repetition trials in two respects, rather than in just one. First, an attended repetition probe appears at the location that was previously attended (responded to), whereas an ignored repetition probe appears at the location that was previously ignored (not responded to). Second, an attended repetition probe appears at the location at which an identical symbol appeared in the prime display (an $\mathrm{O}$ ), whereas an ignored repetition probe appears at the location at which a different symbol appeared in the prime display (see Figure 1). Consequently, differences in priming effects for attended and ignored repetition trials could be due either to attending/ignoring processes or to retrospective matching processes (Kahneman, Treisman, \& Gibbs, 1992; Park \& Kanwisher, 1994).

The purpose of this experiment was to compare repetition effects for attended and ignored repetition conditions, using a procedure that rules out problems introduced by the $\mathrm{X}-\mathrm{O}$ method described above. The procedure used here was an adaptation of that used by Tipper, Weaver, and Houghton (1994; see also Milliken, Tipper, \& Weaver, 1994). As in the $\mathrm{X}-0$ method, two stimuli were displayed on each trial, and the participants were to respond to just one of them. However, in contrast to the $\mathrm{X}-\mathrm{O}$ method, the target stimulus changed from trial to trial. This variable mapping was achieved by displaying two Xs in different colors, together with a color cue. The $X$ that matched the color of the cue was designated the target. With this procedure, repetition of spatial location (the reported dimension) could be varied independently of repetition of color (the dimension used for selection). In other words, a probe target that appeared in the same location as either a prime target or a prime distractor could match or mismatch with the color of the prime stimulus that appeared in that location.

If differences between attended repetition and ignored repetition effects are to be used to draw a distinction between spatial negative priming and location-based inhibition of return, the influence on priming effects of attention to (or more accurately, response to) a location must be separated from the influence of attention to other stimulus attributes, such as identity or color. A pattern of re- sults that would support the distinction between spatial negative priming and inhibition of return would be slowed responses for targets appearing in ignored prime locations but not for those appearing in attended prime locations. By contrast, a pattern of results that would undermine the distinction between spatial negative priming and inhibition of return would be slowed responses for targets appearing in any location that was occupied in the prime display, regardless of whether that prime stimulus was attended or ignored. The key difference between how these effects are evaluated in the present experiment, relative to how they have been evaluated in prior studies, is that attended and ignored repetition effects are compared separately in conditions in which the colors of repeated location stimuli match or mismatch with the prime stimulus that previously occupied that same location.

\section{Method \\ Participants \\ Twenty students from 1st- and 2nd-year psychology courses at McMaster University ( 15 females) participated in the study to earn course credit. The mean age of the participants was 20 years. All the participants had normal or corrected-to-normal visual acuity.}

\section{Apparatus and Stimuli}

The experiment was carried out on a Zenith $386 / 33$ microcomputer with a VGA color monitor. The approximate viewing distance in all cases was $75 \mathrm{~cm}$. All the stimuli were presented in VGA medium resolution graphics mode. Responses were made with a Kraft KC3 joystick interfaced to the computer via a standard game port. RTs were computed using the routines published by Bovens and Brysbaert (1990).

At the start of each trial, four light-gray boxes were drawn on the dark background of the computer monitor to mark the locations where targets and distractors could appear. These boxes were centered on the screen so that the vertical visual angle between the centers of the top and bottom boxes was $2.5^{\circ}$ and the horizontal visual angle between the centers of the left and right boxes was $2.4^{\circ}$. Each box subtended $1.0^{\circ}$ vertically and $0.8^{\circ}$ horizontally. The stimuli themselves (the letter $\mathrm{X}$ ) subtended $0.5^{\circ}$ vertically and $0.4^{\circ}$ horizontally. The rectangular selection cue that appeared in the middle of the display (ASCII character 254) subtended $0.3^{\circ}$ vertically and $0.2^{\circ}$ horizontally. The colors used for presentation of the selection cue, the target, and the distractor were blue, green, purple, and yellow.

\section{Procedure}

Each trial consisted of two displays. Following the convention adopted in previous research, the first of the two displays is referred to as the prime display, and the second is referred to as the probe display. In both the prime and the probe displays, an X appeared inside two boxes while the other two boxes remained empty. A rectangular selection cue also appeared in each display, centered amid the locations of the four boxes. The color of the selection cue indicated to the participants which of the two Xs was the target. For example, if a blue $X$ appeared in the top box, a yellow $X$ appeared in the left box, and a blue rectangle appeared as the selection cue amid the boxes, the target stimulus was the blue $\mathrm{X}$ in the top box. The participant's task was to indicate the location of the target $X$ by making a spatially compatible movement of the joystick (up, down, left, or right). The joystick was located on a table in front of the participant. As such, a target in the top box in the visual display required the joystick to be moved away from the participant, a target in the bottom box required the joystick to be moved toward the participant, a target in the left box required a leftward movement of the 


\section{PRIME}

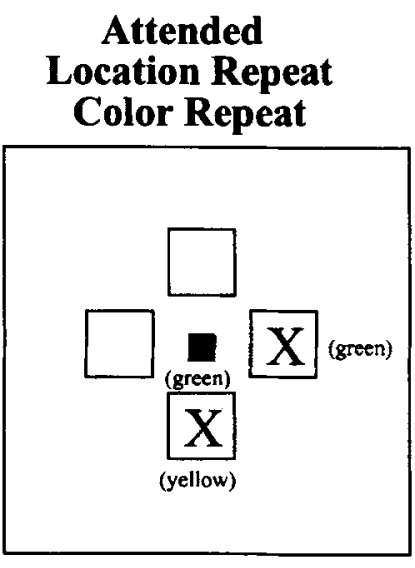

\section{Location Change Color Change}
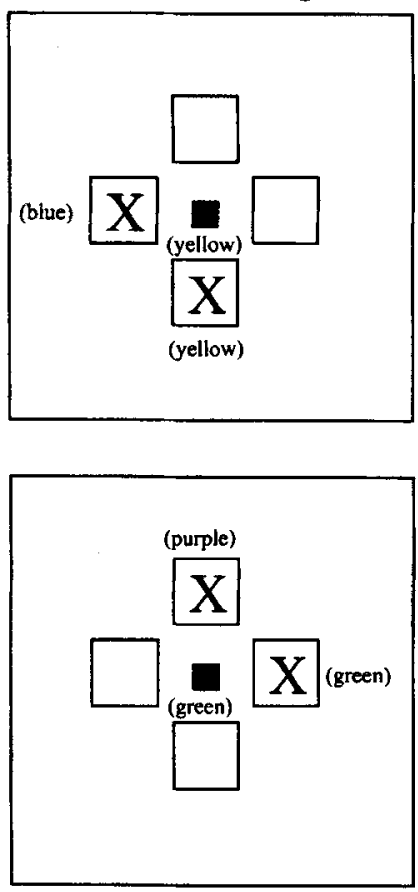

PROBE

Figure 2. Three of the repetition conditions used in Experiment 1. In the attended location-repeat/color-repeat condition, the probe target item (green) is identical in both color and location to the prime target item. In the ignored location-repeat/color-repeat condition, the probe target is identical in location and color to the prime distractor. In the control condition, the prime and the probe items are unrelated to one another.

joystick, and a target in the right box required a rightward movement of the joystick. The participants were asked to make their responses as quickly and accurately as possible.

Each trial was initiated by the press of a start key on the base of the joystick. The four boxes that indicated the potential locations of the target and the distractor appeared immediately and remained on the screen for $1,500 \mathrm{msec}$. The prime target, prime distractor, and central selection cue were then displayed for $157 \mathrm{msec}$. The boxes remained on the screen until the participants made their response. A brief 50-msec click was produced after the joystick response so that the participants knew when their response was recorded by the computer, and a louder beep was also emitted if the participant's response was incorrect. After the participant responded to the prime display, there was a $500-\mathrm{msec}$ response stimulus interval before the probe display appeared. Again, the probe display remained visible for $157 \mathrm{msec}$, a brief $50-\mathrm{msec}$ click followed correct responses, and a louder beep followed incorrect responses. The screen was then cleared, and a prompt to begin the next trial was presented.

The participants completed a practice session in which they made at least two correct responses per condition, followed by a test session in which they completed at least 30 correct trials per condition. The ordering of conditions was random within blocks of trials.

\section{Design}

In all of the conditions in this experiment, the probe distractor appeared in a different location and in a different color than did both prime stimuli. The conditions differed from one another with respect to the relation between the probe target and the two prime stimuli. A 2 (attended/ignored) $\times 2$ (location repetition) $\times 2$ (color repetition) factorial design was used. The attended/ignored factor referred to whether the probe target was related to the attended prime or to the ignored prime. The location repetition factor referred to whether the probe target repeated or changed in location from the critical (attended or ignored) prime. Similarly, the color repetition factor referred to whether the probe target repeated or changed in color from the critical (attended or ignored) prime. Note that, although this design specifies eight conditions, two of these eight conditions are indistinguishable from one another - that is, trials in which neither location nor color repeats are identical in the ignored and attended conditions. These two conditions were created ad hoc, using an odd-even split of the trials in which neither location nor color matched either of the two prime stimuli. To summarize, this design allowed us to compare conditions in which the probe target shared the color, the location, both the color and the location, or neither the color nor the location with either the attended or the ignored prime. Three of the conditions used in this experiment are depicted in Figure 2.

The trials were run in blocks of 12 . The number of trials in each block from each of the eight conditions is displayed in the Appendix. These trial type frequencies ensured that neither the location nor the color of the prime target provided predictive information about the location of the probe target. I 
Table 1A

\begin{tabular}{|c|c|c|c|c|c|c|}
\hline \multirow[b]{4}{*}{ Location } & \multicolumn{5}{|c|}{$\begin{array}{l}\text { Mean Response Times (in Milliseconds) } \\
\text { for Probe Display Responses in Experiment } 1\end{array}$} & \\
\hline & \multicolumn{6}{|c|}{ Attended/Ignored Repetition } \\
\hline & \multicolumn{3}{|c|}{ Attended } & \multicolumn{3}{|c|}{ Ignored } \\
\hline & $\begin{array}{c}\text { Color } \\
\text { Changed }\end{array}$ & $\begin{array}{c}\text { Color } \\
\text { Repeated }\end{array}$ & Difference & $\begin{array}{c}\text { Color } \\
\text { Changed }\end{array}$ & $\begin{array}{c}\text { Color } \\
\text { Repeated }\end{array}$ & Difference \\
\hline Changed & 478 & 457 & 21 & 472 & 471 & 1 \\
\hline Repeated & 506 & 472 & 34 & 497 & 492 & 5 \\
\hline Difference & -28 & -15 & & -25 & -21 & \\
\hline
\end{tabular}

\section{Results}

Correct RTs from each of the eight conditions were submitted to an outlier elimination procedure that ensured that suspiciously large or small RTs were not included in further analyses. The outlier elimination procedure used (see Van Selst \& Jolicoeur, 1994) chooses a criterion for exclusion of data that depends on the number of observations in a cell. Choosing a criterion in this way ensures that more data are not systematically eliminated from cells with fewer observations. In the present experiment, use of this procedure resulted in the elimination of $2.5 \%$ of the RTs. Mean RTs for each condition and each participant were then computed with the remaining observations and were submitted to an analysis of variance (ANOVA) that treated attended/ignored, location repetition, and color repetition as within-subjects factors. Mean RTs and error rates, collapsed across participants, are listed in Tables 1A and 1B.

\section{Response Times}

In the analysis of RTs, there was a significant main effect of location repetition $\left[F(1,19)=27.37, M S_{\mathrm{e}}=721.09\right.$, $p<.001]$. Responses were slower for location-repeated trials than for location-changed trials. There was also a significant attended/ignored $\times$ color interaction $[F(1,19)=$ 17.25, $\left.M S_{\mathrm{e}}=325.05, p<.001\right]$. Whereas RTs for ignored color-repeated and ignored color-changed trials were not significantly different ( 485 vs. $482 \mathrm{msec}$ ), RTs for attended color-repeated trials were significantly faster than those for attended color-changed trials ( $465 \mathrm{vs} .492 \mathrm{msec}$ ). Given the importance of the contrast between attended and ignored conditions and the significant interaction involving the attended/ignored factor, the mean RTs were further examined by performing separate ANOVAs for the attended and the ignored conditions.
In the analysis of the ignored conditions, the only significant result was the main effect of location repetition $\left[F(1,19)=27.31, M S_{\mathrm{e}}=382.19, p<.001\right]$. Responses were slower on location-repeated trials than on locationchanged trials ( 472 vs. $494 \mathrm{msec}$ ).

In the analysis of the attended conditions, there was a significant main effect of color repetition $[F(1,19)=50.05$, $\left.M S_{\mathrm{e}}=289.72, p<.001\right]$, and a significant main effect of location repetition $\left[F(1,19)=12.72, M S_{\mathrm{e}}=732.24, p<\right.$ $.003]$. Responses were faster when the prime and the probe targets were the same color and were faster when the prime and the probe targets appeared in different locations. The location repetition $\times$ color repetition interaction approached significance $(p<.10)$.

Finally, planned comparisons were conducted to contrast location-repeated and location-changed conditions that are intentionally confounded by repetition on the dimension of color. Recall that a confound of this type is inherent to comparisons of attended and ignored repetition effects in many other studies of spatial negative priming. ${ }^{2}$ The comparisons of interest were those between the location-changed/color-changed and locationrepeated/color-repeated conditions. These planned comparisons revealed that responses were significantly faster in the location-changed/color-changed condition than in the location-repeated/color-repeated condition for ignored primes $[t(19)=2.69, p<.02]$, but not for attended primes $(p>.50$; see Table 1A).

\section{Error Rates}

The three-way ANOVA of error rates revealed a similar pattern of results to that for the RTs. There was a significant main effect of location repetition $[F(1,19)=$ $\left.11.67, M S_{\mathrm{e}}=4.66, p<.003\right]$ and a significant interaction between attended/ignored and color repetition

Table $1 \mathrm{~B}$

Mean Error Percentages for Probe

Display Responses in Experiment 1

\begin{tabular}{|c|c|c|c|c|c|c|}
\hline \multirow[b]{3}{*}{ Location } & \multicolumn{6}{|c|}{ Attended/Ignored Repetition } \\
\hline & \multicolumn{3}{|c|}{ Attended } & \multicolumn{3}{|c|}{ Ignored } \\
\hline & $\begin{array}{c}\text { Color } \\
\text { Changed } \\
\end{array}$ & $\begin{array}{c}\text { Color } \\
\text { Repeated }\end{array}$ & Difference & $\begin{array}{c}\text { Color } \\
\text { Changed }\end{array}$ & $\begin{array}{c}\text { Color } \\
\text { Repeated }\end{array}$ & Difference \\
\hline Changed & 1.5 & 0.6 & 0.9 & 0.9 & 1.6 & -0.7 \\
\hline Repeated & 3.0 & 1.9 & 1.1 & 1.9 & 2.9 & -1.0 \\
\hline Difference & -1.5 & -1.3 & & -1.0 & -1.3 & \\
\hline
\end{tabular}


$\left[F(1,19)=8.53, M S_{\mathrm{e}}=4.99, p<.009\right]$. The direction of the main effect of location and the nature of the attended/ ignored $\times$ color repetition interaction were the same as those described for the RTs. As such, there is no evidence that the patterns of RTs described earlier are the result of a speed-accuracy tradeoff.

\section{Discussion}

The critical result in this experiment was the contrast between ignored and attended repetition effects. Importantly, location repetition effects were not different for attended and ignored primes. For both attended and ignored primes, location-repeated trials were responded to more slowly than location-changed trials when the comparisons controlled for the effect of color repetition on performance. By undermining the view that location repetition effects are different for attended and ignored primes, the present results also undermine the distinction between spatial negative priming and inhibition of return.

At the same time, the results of this experiment provide an answer to why attended and ignored repetition effects are not always equivalent in studies of spatial negative priming. In particular, the effect of color repetition differed for attended and ignored primes. There was no effect of color repetition for ignored primes, but there was a reliable facilitory effect of color repetition for attended primes. This result demonstrates that attention to such attributes as color or identity affects priming differently than does attention to stimulus location. Consequently, slowed responses to previously attended locations can be obscured if a further property of the probe target, such as color or identity, also matches that of the previously attended prime. The contrasts between two conditions--one in which neither location nor color was repeated (the location-changed/color-changed condition) and one in which both location and color were repeated (the locationrepeated/color-repeated condition)-demonstrated one way in which slowed responding for repeated locations can be obscured for attended primes, but not for ignored primes. Similarly, differences between attended and ignored repetition effects in prior studies of spatial negative priming may have occurred because attended repetition effects for location are often contaminated by the influence of attention to a particular identity at that location.

\section{EXPERIMENT 2}

The results of Experiment 1 demonstrated that when the effect of attended color repetition is controlled for, a uniform slowing of responses to repeated location targets is revealed. In the present experiment, we attempted to demonstrate this same principle by eliminating, rather than controlling for, the attended color repetition effect. The procedure differed from that of the previous experiment in that the participants were not asked to respond to the prime displays.

\section{Method}

\section{Participants}

Sixteen undergraduate students (12 females) from an introductory psychology class at McMaster University participated in the study for course credit. The mean age of the participants was 20.1 years. All the participants had normal or corrected-to-normal visual acuity.

\section{Procedure}

The procedure was similar to that of Experiment 1 in all respects except those mentioned below. The participants were asked to respond to a target item in the probe display only. As such, the prime display contained two Xs, one in each of two of the four boxes, but did not contain a central color cue. The primes remained visible for $157 \mathrm{msec}$. Following offset of the primes, there was a $500-\mathrm{msec}$ interval, during which only the boxes remained on the screen. The probe display followed this interval. As in Experiment 1, the participants were asked to indicate the location of the $X$ that corresponded in color to the simultaneously presented central cue.

Four of the eight conditions tested in this experiment were similar to those tested in Experiment 1. In all four of these conditions, the probe distractor appeared in a location that was unoccupied in the prime display and in a color that did not match either of the two prime stimuli. The probe target matched one of the prime stimuli in location, in color, or in both location and color, or it mismatched the location and color of both of the prime stimuli. The trials in these four conditions are called distractor-location-changed trials.

For the other four conditions tested in this experiment, the probe target also matched one of the prime stimuli in location, in color, in both location and color, or in neither location nor color. However, these conditions differed from the first four in that the probe distractor appeared in one of the previously occupied locations, rather than in a previously unoccupied location. As such, these are called the distractor-location-repeated conditions. For two of these conditions, the color of the probe distractor mismatched the color of the prime stimulus that appeared previously at the same location, whereas for the other two conditions, the color of the probe distractor matched the color of the prime stimulus that appeared previously at the same location. This distractor color repetition manipulation was done in such a way that the colors of both the probe target and the distractor were repeated or the colors of neither the probe target nor the distractor were repeated. These four distractorlocation-repeated conditions are depicted in Figure 3.

The trials were run in blocks of 12 . The number of trials in each block from each of the eight conditions is displayed in the Appendix. Again, these trial type frequencies ensured that neither the location nor the color of the prime stimuli provided predictive information about the location of the probe target.

\section{Results}

The same outlier elimination procedure as that used in the previous experiment resulted in the exclusion of $2.4 \%$ of the correct RTs from subsequent analyses. Mean RTs for each condition were computed from the remaining observations. These mean RTs and error rates, collapsed across participants, are presented in Tables 2A and 2B.

The data from this experiment were analyzed in the following manner. The first analysis examined mean RTs and error rates for the four conditions that are analogous to those tested in Experiment 1-that is, the distractorlocation-changed conditions. These data were submitted to ANOVAs that treated location repetition and color 


\section{PRIME}

\section{Location Change Color Change}

\section{Location Change Color Repeat}

\section{Location Repeat Color Change}

\section{Location Repeat Color Repeat}
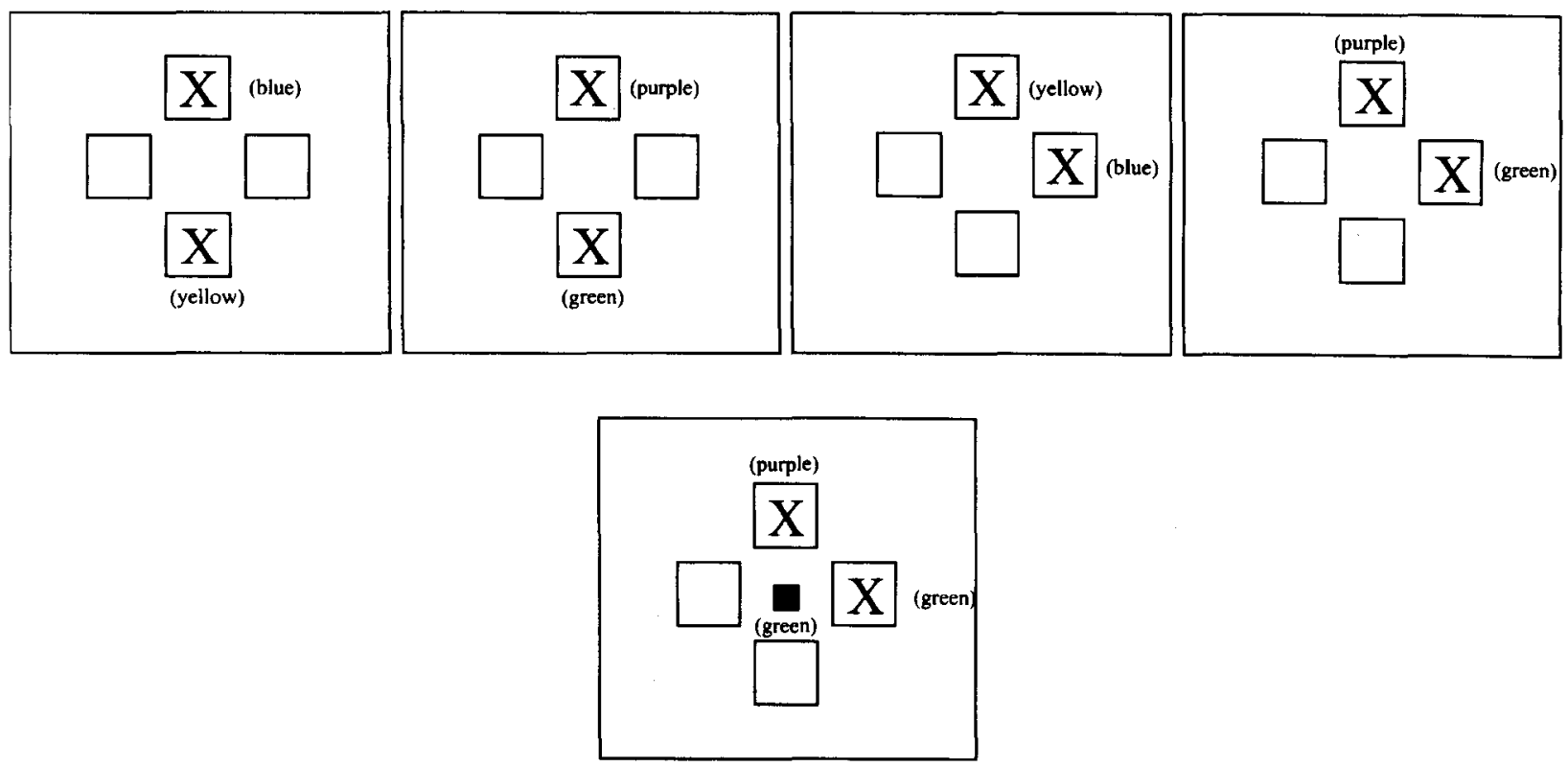

PROBE

Figure 3. The distractor-location-repeated conditions used in Experiment 2. Note that these four conditions are identical to the distractor-location-changed conditions, with the exception that the probe target location matches that of one of the prime items. Furthermore, note that the color-repeated/changed variable for these conditions refers both to the relation between the color of the probe target and the color of the prime items and to the relation between the color of the probe distractor and the color of the stimulus that occupied that same location in the prime display.

repetition as within-subjects factors. The second analysis examined mean RTs and error rates for the distractorlocation-repeated conditions. These data were also submitted to ANOVAs that treated location repetition and color repetition as within-subjects factors. ${ }^{3} \mathrm{~A}$ final planned comparison was conducted to evaluate whether RTs differed for distractor-location-changed and distractorlocation-repeated trials.

The ANOVA of RTs from the distractor-locationchanged conditions revealed a significant main effect of location repetition $\left[F(1,15)=19.24, M S_{\mathrm{e}}=584.89\right.$, $p<.001]$. RTs were significantly longer for locationrepeated trials $(552 \mathrm{msec})$ than for location-changed trials $(523 \mathrm{msec})$. The interaction between location repetition and color repetition approached significance $(p<$ .10). The means presented in Table $2 \mathrm{~A}$ indicate that the location repetition effect was slightly larger when the colors mismatched ( $524 \mathrm{vs} .555 \mathrm{msec}$ ) than when they matched ( 527 vs. $549 \mathrm{msec}$ ).

In the corresponding analysis of error rates, there was also a significant main effect of location repetition $\left[F(1,15)=8.00, M S_{\mathrm{e}}=1.94, p<.02\right]$. More errors were made for location-repeated trials than for location-changed trials. There was also a marginally significant interaction between location repetition and color repetition $(p<.10)$. However, the nature of this interaction was opposite that described above for the RTs.

The ANOVA of RTs from the distractor-locationrepeated conditions revealed a significant main effect of location repetition $\left[F(1,15)=58.09, M S_{\mathrm{e}}=286.17, p<\right.$ $.001]$. RTs were significantly longer for locationrepeated trials $(546 \mathrm{msec})$ than for location-changed trials $(514 \mathrm{msec})$. There were no other significant effects in this analysis $(F<1)$ and no significant effects in the corresponding analysis of error rates.

Finally, planned comparisons revealed faster RTs in the distractor-location-repeated conditions $(530 \mathrm{msec})$ than in the distractor-location-changed conditions $[539 \mathrm{msec}$; $t(15)=2.54, p<.03$ ] and a lower error rate in the distractor-location-repeated conditions (.002) than in the distractor-location-changed conditions (.011).

\section{Discussion}

The critical result in this experiment was that the attended color repetition effect observed in Experiment 1 was not observed. The elimination of this effect revealed uniformly slower RTs to location-repeated targets than to location-changed targets. This result confirms that at- 
Table 2A

Mean Response Times (in Milliseconds) for Probe Display Responses in Experiment 2

\begin{tabular}{|c|c|c|c|c|c|c|}
\hline \multirow[b]{3}{*}{ Location } & \multicolumn{6}{|c|}{ Distractor Location } \\
\hline & \multicolumn{3}{|c|}{ Changed } & \multicolumn{3}{|c|}{ Repeated } \\
\hline & $\begin{array}{c}\text { Color } \\
\text { Changed }\end{array}$ & $\begin{array}{c}\text { Color } \\
\text { Repeated }\end{array}$ & Difference & $\begin{array}{c}\text { Color } \\
\text { Changed }\end{array}$ & $\begin{array}{c}\text { Color } \\
\text { Repeated }\end{array}$ & Difference \\
\hline Changed & 524 & 527 & -3 & 513 & 514 & -1 \\
\hline Repeated & 555 & 549 & 6 & 543 & 548 & -5 \\
\hline Difference & -31 & -22 & & -30 & -34 & \\
\hline
\end{tabular}

Note-For distractor-location-changed trials (left side of table), color changed/ repeated refers to the color of the target only. On these trials, the distractor color always changed. For distractor-location-repeated trials (right side of table), color changed/repeated refers to the color of both the target and the distractor.

tending to a target color can produce priming effects that are opposite in sign to those associated with attending to a location. When these attended color repetition effects were measured separately from attended location repetition effects (Experiment 1) or were eliminated by asking the participants to respond to the probe display only (Experiment 2), responses to targets in any previously occupied location were slowed, relative to targets in previously unoccupied locations. These results demonstrate that location repetition effects may be no different for previously attended and previously ignored locations.

From the perspective of the literature on inhibition of return, these results might be interpreted as confirmation that inhibition of return can be obtained in selective discrimination tasks (Lupiáñez et al., 1997; Pratt, 1995; Pratt \& Abrams, 1999; see also Experiments 3A and 3B). From the perspective of the negative priming literature, the present results demonstrate that spatial negative priming effects can occur without requiring the participant to select overtly between a prime target and a distractor (see Park \& Kanwisher, 1994, for similar demonstrations in spatial localization tasks; Milliken \& Joordens, 1996, and Milliken, Joordens, Merikle, \& Seiffert, 1998, for similar demonstrations in word-naming tasks; and Ortells \& Tudela, 1996, for a similar demonstration in a lexical decision task). Although the attended color repetition effect in Experiment 1 gives the appearance that negative priming is related to the prime selection task, the results of Experiment 2 demonstrate that this color repetition effect masks an underlying similarity between attended and ignored location repetition effects.

Finally, the convergence between spatial negative priming and inhibition of return demonstrated here implicitly rules out a prominent theoretical account of spatial negative priming. Park and Kanwisher (1994) examined spatial negative priming, using several variants of the procedure introduced by Tipper et al. (1990; see Figure 1). They observed negative priming when a probe target $O$ appeared in a location previously occupied by an $X$ in the prime display, regardless of whether that location was attended or ignored. Similarly, they observed positive priming when the probe target $\mathrm{O}$ appeared in a location previously occupied by an $\mathrm{O}$ in the prime display, regardless of whether that location was attended or ignored. Consequently, Park and Kanwisher attributed negative priming to the effects of a symbol mismatch at one location in consecutive displays, rather than to attentional processes used to select a target and ignore a distractor. The present results confirm that negative priming is not related to overt selection between a target and a distractor but do not support the mismatching hypothesis of Park and Kanwisher (1994; see also Milliken et al., 1994; Tipper, Weaver, \& Milliken, 1995). In particular, it is noteworthy that negative priming was observed in this experiment in a condition in which the target and the distractor were both identical across the prime and probe displays (see the rightmost of the four data columns in Table 2A). Thus, the feature mismatching account of spatial negative priming

Table 2B

Mean Error Percentages for Probe Display Responses in Experiment 2

\begin{tabular}{cccccccc}
\hline & \multicolumn{4}{c}{ Distractor Location } \\
\cline { 2 - 4 } & \multicolumn{3}{c}{ Changed } & & \multicolumn{3}{c}{ Repeated } \\
\cline { 2 - 4 } \cline { 5 - 7 } Location & $\begin{array}{c}\text { Color } \\
\text { Changed }\end{array}$ & $\begin{array}{c}\text { Color } \\
\text { Repeated }\end{array}$ & Difference & $\begin{array}{c}\text { Color } \\
\text { Changed }\end{array}$ & $\begin{array}{c}\text { Color } \\
\text { Repeated }\end{array}$ & Difference \\
\hline Changed & 0.6 & 0.6 & 0.0 & & 0.1 & 0.5 & -0.4 \\
Repeated & 0.9 & 2.3 & -1.4 & & 0.0 & 0.4 & -0.4 \\
Difference & -0.3 & -1.7 & & & 0.1 & 0.1 & \\
\hline
\end{tabular}

Note-For distractor-location-changed trials (left side of table), color changed/repeated refers to the color of the target only. On these trials, the distractor color always changed. For distractor-location-repeated trials (right side of table), color changed/repeated refers to the color of both the target and the distractor. 
appears to be incorrect. Indeed, this theoretical account would have to be incorrect, if spatial negative priming and inhibition of return have the same cause, since inhibition of return does not depend on such mismatches.

\section{EXPERIMENTS 3A AND 3B}

The primary focus of this article is the relation between spatial negative priming and inhibition of return. The results of Experiments 1 and 2 suggest that these two phenomena may have the same cause. Across these two experiments, when attended color repetition effects were removed either with the appropriate control condition or by an instruction not to respond to the prime, slowed responses for location-repeated trials occurred regardless of whether the critical prime stimulus was selected for, selected against, or simply not responded to. These results suggest that the location repetition effects observed in Experiment 1 need not be distinguished from those observed in Experiment 2. Pushing the argument a step further, if the location repetition effects observed in Experiment 2 are examples of inhibition of return and the location repetition effects observed in Experiment 1 are examples of negative priming, it follows that spatial negative priming and inhibition of return may have a common underlying cause.

A possible objection to this conclusion is that the location repetition effects observed in Experiment 2 may not be examples of inhibition of return. Rather, all of the location repetition effects observed in Experiments 1 and 2 could be examples of negative priming. In support of this argument, consider that the probe task in both Experiments 1 and 2 required the participants to discriminate between a target and a distractor before selectively performing a localization response for the target. Interestingly, inhibition of return is often less robust in studies that require choice discrimination than in studies that require simple detection or localization of a visual target (Klein \& Taylor, 1994; Shimojo, Tanaka, Hikosaka, \& Miyauchi, 1996; Terry et al., 1994). Thus, the robust slowing of responses to location-repeated probes in the discrimination tasks used here could indicate that these effects are not related to inhibition of return.

Counter to this argument, it has been shown that inhibition of return does occur in some discrimination tasks (Lupiáñez et al., 1997; Pratt, 1995; Pratt \& Abrams, 1999). Therefore, what must be established is whether the type of discrimination task used here is one in which inhibition of return might be expected to occur. To address this issue, two separate experiments were conducted. In Experiment $3 \mathrm{~A}$, a single prime stimulus was presented in one of the four marked locations on each trial. The participants were not required to respond to this prime stimulus. A probe display then appeared that contained a single stimulus, either in the same location as or in a different location than the prime stimulus. As such, the procedure for this experiment was as similar to that of a conventional inhibition of return study as possible, with the constraint that the stimulus display and response requirements were similar to those of Experiments 1 and 2. Of course, slower responses to location-repeated than to location-changed targets were predicted for this experiment.

In Experiment 3B, the procedure was similar to that of Experiment $3 \mathrm{~A}$, with the exception that two stimuli were presented in each probe display, together with a color cue, as in Experiments 1 and 2. In effect, a discrimination component was added to the procedure of Experiment $3 \mathrm{~A}$. The purpose of this experiment was to evaluate whether adding this discrimination component to a simple target localization task would disrupt the inhibition of return predicted to occur in Experiment 3A. If such a disruption were to occur, it would challenge the view that the spatial localization effects observed in Experiments 1 and 2 are related to inhibition of return. In contrast, if the addition of a discrimination component to the task were to leave the inhibition of return effect intact, there would be no reason to doubt that the location repetition effects observed in Experiments 1 and 2 are related to inhibition of return.

\section{Method}

\section{Participants}

Eight undergraduate students ( 6 females) participated in Experiment $3 \mathrm{~A}$, and 16 undergraduate students ( 14 females) participated in Experiment 3B. All the participants were students in an introductory psychology class at McMaster University and received course credit for their participation. The mean age of the participants in both Experiments $3 \mathrm{~A}$ and $3 \mathrm{~B}$ was 19.3 years. All the participants had normal or corrected-to-normal visual acuity.

\section{Procedure}

The procedure used in these experiments was similar to that of Experiment 2, with the exceptions noted below.

Experiment 3A. A single $X$ appeared in one of the four boxes in both the prime and the probe displays. The participants were asked to respond by indicating the location of the lone target stimulus in the probe display only. The conditions tested in Experiment $3 \mathrm{~A}$ were the same as the distractor-location-changed conditions tested in Experiment 2. In each block of 12 trials, there were 6 from the location-changed/color-changed condition, 3 from the locationchanged/color-repeated condition, 2 from the location-repeated/ color-changed condition, and 1 from the location-repeated/colorrepeated condition. This composition of trials within a block ensured that neither the prime location nor the prime color provided predictive information about the location of the following probe target.

Experiment 3B. A single $X$ appeared in one of the four boxes in the prime display, and a single $\mathrm{X}$ appeared in each of two of the four boxes in the probe display. The probe target $\mathrm{X}$ was designated by a color cue that appeared centrally, as in Experiments 1 and 2. The participants were asked to respond by indicating the location of the target item in the probe display only. The conditions tested included the four distractor-location-changed conditions from Experiment 2 and a distractor-location-repeated condition. In the distractor-locationrepeated condition, the probe distractor appeared in the same location as, but in a different color than, the lone prime stimulus, whereas the probe target appeared in one of the unoccupied prime locations and in a different color than the prime stimulus. Trials were run in blocks of 12 . The number of trials within a block from each condition is displayed in the Appendix. These trial type frequencies ensured that 
Table 3A

\begin{tabular}{|c|c|c|c|c|c|c|}
\hline \multirow[b]{2}{*}{ Location } & \multicolumn{3}{|c|}{ Experiment 3A } & \multicolumn{3}{|c|}{ Experiment 3B } \\
\hline & $\begin{array}{c}\text { Color } \\
\text { Changed }\end{array}$ & $\begin{array}{c}\text { Color } \\
\text { Repeated }\end{array}$ & Difference & $\begin{array}{c}\text { Color } \\
\text { Changed }\end{array}$ & $\begin{array}{c}\text { Color } \\
\text { Repeated }\end{array}$ & Difference \\
\hline Changed & 399 & 399 & 0 & 501 & 492 & 9 \\
\hline Repeated & 456 & 450 & 6 & 535 & 542 & -7 \\
\hline Difference & -57 & -51 & & -34 & -50 & \\
\hline
\end{tabular}

neither the location nor the color of the prime stimuli provided predictive information about the location of the probe target.

\section{Results}

Correct RTs for each condition were submitted to the same outlier analysis as that used in the previous experiments. This procedure resulted in the elimination of $2.0 \%$ of the observations from further analyses in Experiment $3 \mathrm{~A}$ and $2.2 \%$ of the observations from further analyses in Experiment 3B. Mean RTs for each condition were computed from the remaining observations. These mean RTs and error rates, collapsed across participants, are presented in Tables 3A and 3B.

Experiment 3A. The mean RTs and error rates from each of the conditions were submitted to an ANOVA that treated location repetition and color repetition as withinsubjects variables. In the analysis of RTs, the only significant effect was the main effect of location repetition $\left[F(1,7)=41.59, M S_{\mathrm{e}}=563.83, p \leq .001\right]$. The responses were slower to location-repeated probes $(453 \mathrm{msec})$ than to location-changed probes $(399 \mathrm{msec})$. The corresponding analysis of error rates revealed a main effect of location repetition that approached significance $[F(1,7)=4.95$, $\left.M S_{\mathrm{e}}=1.42, p \leq .07\right]$. This effect corresponded with that for the RTs in that more errors were made on locationrepeated trials $(1.8 \%)$ than on location-changed trials $(0.9 \%)$. No other effects in either the RT or the error rate analysis approached significance. ${ }^{4}$

Experiment 3B. The first analyses examined mean RTs and error rates for the four distractor-locationchanged conditions. These data were submitted to ANOVAs that treated location repetition and color repetition as within-subjects factors. A single planned comparison between one of the distractor-location-changed conditions (location-changed/color-changed) and the lone distractor-location-repeated condition was also performed.
The analysis of RTs revealed a significant main effect of location repetition $\left[F(1,15)=73.46, M S_{\mathrm{e}}=387.66\right.$, $p<.001]$. Responses were slower for location-repeated trials $(539 \mathrm{msec})$ than for location-changed trials $(497 \mathrm{msec})$. There was also a marginally significant interaction between location repetition and color repetition $(p<.10)$. The difference between location-repeated and locationchanged trials was marginally larger for color-repeated than for color-changed trials. In the corresponding analysis of error rates, there was a significant main effect of location repetition $\left[F(1,15)=11.08, M S_{\mathrm{e}}=2.04, p<.005\right]$. More errors were made on location-repeated trials $(2.6 \%)$ than on location-changed trials (1.4\%). The interaction between location repetition and color repetition was not significant $(F<1)$.

The planned comparison revealed significantly faster RTs in the distractor-location-repeated condition (484 $\mathrm{msec}$ ) than in the distractor-location-changed (locationchanged/color-changed) condition [501 msec; $t(15)=$ $5.81, p<.001]$, confirming the distractor repetition effect observed in Experiment 2 (see also Tipper, Bourque, Anderson, \& Brehaut, 1989; Tipper \& Cranston, 1985). The pattern of error rates corresponded with that of the RTs for this comparison, although the difference in error rates was only marginally significant $(p<.10)$.

\section{Discussion}

The procedure used in Experiment 3A was typical of those used to measure inhibition of return. Consequently, it was predicted that this procedure would result in slower responses for location-repeated than for locationchanged trials. The procedure used in Experiment $3 \mathrm{~B}$ differed only in that a discrimination component was added to the probe task; the participants had to locate an X that matched the central color cue, rather than locating a single $\mathrm{X}$. The results indicate clearly that adding a discrimination component to the probe display does not elimi-

Table 3B

Mean Error Percentages for Probe Display Responses in Experiment 3

\begin{tabular}{lccccccc}
\hline & \multicolumn{3}{c}{ Experiment 3A } & & \multicolumn{3}{c}{ Experiment 3B } \\
\cline { 2 - 4 } \cline { 6 - 8 } Location & $\begin{array}{c}\text { Color } \\
\text { Changed }\end{array}$ & $\begin{array}{c}\text { Color } \\
\text { Repeated }\end{array}$ & Difference & & $\begin{array}{c}\text { Color } \\
\text { Changed }\end{array}$ & $\begin{array}{c}\text { Color } \\
\text { Repeated }\end{array}$ & Difference \\
\hline Changed & 0.8 & 0.9 & -0.1 & & 1.6 & 1.2 & 0.4 \\
Repeated & 1.6 & 2.0 & -0.4 & & 2.5 & 2.7 & -0.2 \\
Difference & -0.8 & -1.1 & & & -0.9 & -1.5 & \\
\hline
\end{tabular}


nate the conventional inhibition of return effect, as measured with the present procedure (see also Pratt \& Abrams, 1999). As such, these results undermine the argument that the location repetition effects in Experiments 1 and 2 reflect negative priming, but not inhibition of return.

The results of the present experiment might be used instead to argue that the location repetition effects reported here reflect inhibition of return, but not negative priming. In support of this argument, negative priming measured with a variety of procedures has been shown to occur only when the probe task requires selection between a target and a distractor (Lowe, 1979; Milliken et al., 1998; Moore, 1994; Tipper et al., 1990; Tipper \& Cranston, 1985). If this were the case here, negative priming effects ought to have occurred in Experiment 3B, but not in Experiment 3A. However, most demonstrations of the dependence of negative priming on probe selection have occurred with procedures that require identification responses, rather than localization responses (Neill, Terry, \& Valdes, 1994; but see Tipper et al., 1990). Indeed, this difference is one that has been used to argue that spatial negative priming reflects different processes than negative priming measured in other tasks (Fox, 1995; May et al., 1995; Neill et al., 1994). As such, the fact that the location repetition effects in these experiments did not depend on a selective attention probe task is quite consistent with the spatial negative priming literature.

\section{GENERAL DISCUSSION}

The purpose of the research described here was to examine the relation between spatial negative priming and inhibition of return. Note that spatial negative priming is presumed to reflect slowed processing at a previously ignored location, whereas inhibition of return is presumed to reflect slowed processing at a previously attended location. This distinction rests on the observation of qualitatively different priming effects for attended and ignored repetition conditions in selective attention studiespositive priming for attended repetitions and negative priming for ignored repetitions (Lowe, 1985; Tipper, 1985; Tipper et al., 1990).

In Experiment 1, attended repetition and ignored repetition effects did differ. However, the critical difference between attended and ignored repetition effects concerned the color dimension, rather than the location dimension. Specifically, attended color repetitions resulted in faster responses than did attended color changes. This attended color repetition effect has an interesting implication. If comparisons between location-repeated and location-changed conditions are made without controlling for the attended color repetition effect, one might conclude that attended and the ignored location repetition effects differ (note the difference between the attended and the ignored location-repeated/color-repeated conditions in Table 1A). This issue is important in the present context because the procedure often used to measure spatial negative priming does not control well for the ef- fect of attention to attributes other than spatial location. Consequently, past failures to observe slowed responding in the attended repetition condition of spatial negative priming studies may have occurred because an attended repetition effect on a dimension other than spatial location (e.g., identity) masked an underlying spatial inhibition of return effect. As a result, evidence used to distinguish between negative priming and inhibition of return may not distinguish between the two phenomena at all (see also Christie \& Klein, 1999).

In Experiment 2, the attended color repetition effect was eliminated simply by asking the participants not to respond to the prime display. In the absence of an attended color repetition effect, responses to location-repeated trials were uniformly slower than those to locationchanged trials. Although it could be argued that inhibition of return effects typically do not occur with the type of probe tasks used in Experiments 1 and 2, the results of Experiments $3 \mathrm{~A}$ and $3 \mathrm{~B}$ demonstrated similar location repetition effects for probe tasks that did and did not require discriminating between a target and a distractor.

One conclusion that may be drawn from these results is that spatial negative priming and inhibition of return measure the same processes. In support of this conclusion, we dismissed the alternative interpretation that the results of Experiments 1 and 2 are unrelated to inhibition of return. However, a second alternative interpretation is possible. In particular, it could be argued that all of the results of the present studies provide measures of inhibition of return and that none provides a measure of spatial negative priming. If this were the case, these results would be mute to the issue of convergence between the two phenomena. In support of this alternative explanation, it could be argued that the selective attention procedure used in Experiment 1 was not the same as that typically used to measure spatial negative priming. In most such studies, the target is a constant symbol determined prior to the beginning of the experimental session, whereas in the present experiments the target was selected on the basis of a simultaneously presented color cue.

We must acknowledge that this procedural difference may have produced an attended color repetition effect for reasons that are not directly relevant to studies of spatial negative priming that use the more conventional $\mathrm{X}-\mathrm{O}$ localization procedure. However, the particular change adopted here had the purpose of separating the contributions of attended location repetition and attended color repetition to performance. The results demonstrate that, under the testing conditions used here, attended location repetition and attended color repetition effects differ. The conclusion that we favor is that a related difference between location and identity priming (or between location and object-based priming) effects underlies differences between attended and ignored repetition effects in studies of spatial negative priming. Our confidence in such a conclusion would be heightened if a similar pattern of attended repetition effects could be shown with a procedure that more closely resembles the $\mathrm{X}-\mathrm{O}$ spatial 
localization procedure. For example, rather than defining target stimuli with a simultaneously presented color cue, targets could be defined before the experimental session as being either of two colors - say, red or green. With this procedure, a red target could be followed by either a red or a green target in the same spatial location. If attended repetition responses were slowed only for green targets that followed red targets in the same spatial location, this result would show that the concerns raised in this article are not a product of the idiosyncratic procedure that we used.

In fact, this type of procedure was employed recently by Pratt and Abrams (1999) to establish why inhibition of return does not always occur in discrimination tasks (Klein \& Taylor, 1994; Shimojo et al., 1996; Terry et al., 1994). Their results also demonstrated that inhibition of return can be overridden by a priming effect based on a dimension other than spatial location. Specifically, when participants were required to orient overtly toward a peripheral cue (i.e., make an eye movement toward the cue), the spatial inhibition of return effect did not occur when the symbol that defined the cue was the same as the target. In contrast, when participants were required to orient covertly toward a peripheral cue, the spatial inhibition of return effect occurred for both matching and mismatching symbols at the cued location.

The results from the overt orienting procedure of Pratt and Abrams (1999) appear to parallel those from Experiment 1 , in which the participants made overt responses to both the prime and the probe, whereas those from the covert orienting procedure parallel those from the other experiments reported here, in which a response was not required to the prime. These empirical parallels suggest that the results reported here are not the product of our cuing procedure. Rather, opposing effects of repetition for spatial location and for other stimulus dimensions (e.g., identity, color) appear to be common and should be taken into account when making inferences about attentional influences on priming or cuing effects. In the context of the Pratt and Abrams study, these opposing effects provided an explanation for why inhibition of return is sometimes not observed in discrimination tasks. In the context of the present study, these opposing effects were used to undermine the empirical basis for distinguishing between spatial negative priming and inhibition of return.

The remainder of this discussion is devoted to two theoretical perspectives on how inhibition of return and negative priming might share a common cause. One perspective focuses on inhibitory processes that occur upon encoding of the prime or the cue, whereas the other perspective focuses on constructive retrieval processes that occur after onset of the probe.

\section{An Inhibitory Process Account}

Both negative priming and inhibition of return are commonly considered to reflect attentional processes (Posner \& Cohen, 1984; Tipper, 1985). However, the Houghton and Tipper (1994) neural network model of attention was the first to show how the two effects might be related (see Houghton \& Tipper, 1994, for a full account of the model, henceforth referred to as the HT model). The central problem addressed by the model is that of responding to a prespecified target in the presence of competing distractors. It is proposed that many inputs are activated in parallel, leading to the activation of competing responses (e.g., Coles, Gratton, Bashore, Eriksen, \& Donchin, 1985; Eriksen \& Eriksen, 1974; Stroop, 1935). In the model, selection involves the maintenance in working memory of a template, which describes the properties of to-be-selected inputs (e.g., the red object or the stimulus appearing at a particular location). Activated representations that match this template receive excitatory feedback, whereas those that do not generate inhibitory feedback. Response efficiency to a subsequent probe stimulus then reflects the excitatory and inhibitory processing that allows selection of the target item to occur.

The HT model applies whenever a target input can be distinguished by a representable property (the template). Note that distractors need not occur simultaneously with the target, a situation exemplified by target detection in rapid serial visual presentation tasks (see Potter, 1993; Raymond, Shapiro, \& Arnell, 1992; Weichselgartner \& Sperling, 1988). In this case, any inputs occurring prior to the target are assumed to mismatch the template and receive inhibitory feedback. However, this process of matching and initiation of inhibition takes time, and nonmatching inputs may initially achieve high activation levels (see Houghton \& Tipper, 1994, for simulations). This property of the model fits nicely with the results from inhibition of return studies, in which presentation of an uninformative cue is followed shortly (e.g., 150 or $500 \mathrm{msec}$ ) by a target. The typical result obtained is a benefit for targets at the cued location when the target follows the cue shortly afterward (within $150 \mathrm{msec}$ ) and a cost for targets at the cued location at longer intervals (beyond $300 \mathrm{msec}$ ).

The way in which the temporal pattern of selection in the HT model can produce inhibition of return is described in detail, with computer simulations, in Houghton and Tipper (1994). Briefly, there is a period of perceptual activity produced by the cue before inhibitory feedback begins. This period may be in the range of $100-150 \mathrm{msec}$, the same range during which cuing benefits have been observed (see also Houghton, Tipper, Weaver, \& Shore, 1996, and Lowe, 1985, for evidence that negative priming also takes time to develop). This initial activation is then followed by an inhibitory rebound, as the perceptual input triggers a mismatch with the target template (see Figure 18 in Houghton \& Tipper, 1994, and note 5). Inhibition of return may then provide a measure of this inhibitory rebound.

In the present set of studies, all the procedures required the participants to ignore a prime stimulus. For example, Experiment 1 used a conventional negative priming procedure, in which target and distractor are compared with a template so that action can be selectively directed to the target. The HT model assumes that the prime distractor 
mismatches the target template and is, therefore, subject to inhibition. By contrast, in Experiment $3 \mathrm{~A}$, a single $\mathrm{X}$ was presented in the prime display, followed by a single $\mathrm{X}$ in the probe display. The participants were required to ignore the first $X$ in the prime and to localize the second $X$ in the probe. Although a localization response is required throughout the experiment and is "afforded" by the prime stimulus, it must be withheld. In this case, the feature that distinguishes the target from the distractor is temporal order, and some inhibition of the perceptionaction coupling must take place to prevent inappropriate responding. In this way, the template match/mismatch process can explain both inhibition of return and negative priming.

In summary, the HT model explains negative effects of stimulus repetition by reference to inhibitory processing. This inhibitory processing is triggered by a mismatch between a presented stimulus and a task-based attentional template. This mismatch-triggered inhibition can explain negative effects of stimulus repetition in ignored repetition conditions, and in conditions in which primes are displayed but not responded to by the participant. Furthermore, a range of other empirical phenomena related to the demands of rapid serial responding, such as inhibition of stimuli that have previously been attended and responded to, may be understood by reference to a related self-inhibition process proposed in Houghton and colleagues' competitive queuing model of serial behavior (Houghton, 1990; Houghton \& Hartley, 1996; for more detailed discussions of the relationship between inhibition in serial action and selective attention, see Houghton, 1994, and Houghton \& Tipper, 1996).

\section{A Constructive Retrieval Account}

An alternative explanation for both negative priming and inhibition of return derives from recent studies that demonstrate a dependence of negative priming on retrieval processes (Milliken et al., 1998; see also Neill \& Mathis, 1998; Neill, Valdes, Terry, \& Gorfein, 1992). In particular, this account focuses on the role of novelty, or temporal distinctiveness, during a constructive retrieval process (see also Milliken et al., 1998). Although the notion of attentional capture by novelty is well supported in other empirical work (Yantis \& Jonides, 1984, 1990), the role of novelty in studies of priming and of cuing may often be obscured by an opposing influence that results in repetition priming.

The central premise of this account is that both negative priming and inhibition of return are ultimately determined by processes that occur after onset of the probe stimulus. In accord with this premise, the view that retrieval processes determine priming effects has gained considerable support (see Kahneman et al., 1992; Logan, 1988; Neill et al., 1992; Ratcliff \& McKoon, 1988; Whittlesea \& Jacoby, 1990; for a review, see Tenpenny, 1995). For example, Kahneman et al. proposed that onset of a probe initiates a retrospective correspondence process, the function of which is to determine whether that probe can be integrated with an existing episodic memory representation. According to Kahneman et al., this correspondence process is based primarily on spatiotemporal properties. If a probe does correspond spatiotemporally to an existing episodic representation, the perceptual representation of the probe is integrated with that memory representation. In contrast, if the probe does not correspond spatiotemporally to an existing episodic representation, a new episodic representation is created.

Although the Kahneman et al. (1992) framework was forwarded to explain object-specific repetition benefits, by considering the role of novelty in capturing attention (Yantis \& Jonides, 1984, 1990), it can be extended to accommodate findings such as negative priming and inhibition of return. In particular, the Kahneman et al. framework proposes that location-changed targets are responded to by creating a new episodic representation, rather than by updating an existing episodic representation. If we assume that one of the functions of attention is to bind a perceptual event to an episodic context, the capture of attention by a location-changed target would serve precisely the function needed - the creation of a new episodic representation. Thus, our extension to the Kahneman et al. framework includes an episodic integration process that favors response to repeated events, as well as an attentional process that favors processing for novel over repeated events. Consequently, priming effects should depend on the relative efficiencies of these two processes. To the extent that the integration process on repeated trials is efficient, repetition priming should occur. However, if this integration process is inefficient, a new episodic representation may be created faster on location-changed trials than an old episodic representation can be updated on location-repeated trials; that is, negative effects of stimulus repetition, such as inhibition of return and negative priming, may occur.

The time course of inhibition of return can be accounted for in this framework by assuming that the efficiency of spatiotemporal integration on cued trials decreases as the SOA increases. At short SOAs, the benefit of a fast integration process on location-repeated trials outweighs that of attention capture on location-changed trials, and a positive cuing effect results. However, a decrease in efficiency of integration at longer SOAs reveals the benefit of attention capture, expressed as an inhibition of return effect. By this view, attention to the cued location at short SOAs plays an important role in the efficient integration of memory and perception, whereas disengagement of attention from the cued location at longer SOAs leaves the observer vulnerable to inefficient integration of memory and perception. Furthermore, if location differs from other attributes, such as color or identity, in the cost of inefficient integration on cued trials, relative to the benefit of attention capture on uncued trials, this would address a central issue raised in this article. In particular, inefficient spatial integration may be overridden by effi- 
cient integration based on stimulus dimensions other than spatial location. ${ }^{6}$

Note that this account of negative priming and inhibition of return differs from inhibition-based accounts in that the basis of the slowed RTs on repeated trials is the persistence of a memorial representation of the prime. The consequences of this persistence depend critically on whether it can provide the basis for efficient integration with a subsequent probe on location-repeated trials. If not, the benefit of attention capture for location-changed trials is revealed.

\section{Summary}

The results from the experiments presented here suggest that the distinction between spatial negative priming and inhibition of return effects may be limited to the procedures used to measure them. In particular, failures to observe slowed responses for attended repetition trials in selective attention tasks may be attributed to the effect of attention on priming for attributes other than spatial location. Failures to observe inhibition of return in discrimination tasks may have a similar cause (Pratt \& Abrams, 1999). These effects may obscure an underlying similarity between the processes that cause inhibition of return and spatial negative priming. ${ }^{7}$

Two theoretical accounts were offered, both of which attribute negative priming and inhibition of return to a common cause. The inhibition account (see Houghton \& Tipper, 1994, for details) attributes both negative priming and inhibition of return to inhibitory processing of the first of two events. This inhibition is triggered by a mismatch between the perceptual activity of the first event and an attentional template and is measured in response to the second of two events. The constructive retrieval account views both negative priming and inhibition of return as emergent consequences of processing that occurs after presentation of the second of two stimulus events (see Milliken et al., 1998; Neill \& Mathis, 1998). Although the results reported in this article do not distinguish between the two frameworks, they do suggest that a common theoretical framework for explaining negative priming and inhibition of return should be sought. Whether either of these frameworks, or some rapprochement of both frameworks, adequately captures the convergence of these two phenomena is an issue that we are currently pursuing.

\section{REFERENCES}

AвRAms, R. A., \& Dobkin, R. S. (1994). Inhibition of return: Effects of attentional cuing on eye movement latencies. Journal of Experimental Psychology: Human Perception \& Performance, 20, 467-477.

Bovens, N., \& BRysbaerT, M. (1990). IBM PC/XT/AT and PS/2 Turbo Pascal timing with extended resolution. Behavior Research, Methods, Instruments, \& Computers, 22, 332-334.

Christie, J., \& KLeIN, R. M. (1999). Negative priming for spatial location? Manuscript submitted for publication.

Coles, M. G. H., Gratton, B., Bashore, T. R., Eriksen, C. W., \& DonCHIN, E. (1985). A psychophysiological investigation of the con- tinuous flow model of human processing. Journal of Experimental Psychology: Human Perception \& Performance, 11, 529-553.

ERIKSEN, B. A., \& ERIKSEN, C. W. (1974). Effects of noise letters upon the identification of a target letter in a nonsearch task. Perception \& Psychophysics, 16, 143-149.

Fox, E. (1995). Negative priming from ignored distractors in visual selection: A review. Psychonomic Bulletin \& Review, 2, 145-173.

Gibson, B. S., \& EGETH, H. (1994). Inhibition of return to object-based and environment-based locations. Perception \& Psychophysics, 55, 323-339.

Houghton, G. (1990). The problem of serial order: A neural network model of sequence learning and recall. In R. Dale, C. Mellish, \& $\mathrm{M}$. Zock (Eds.), Current research in natural language generation (pp. 287-319). London: Academic Press.

Houghton, G. (1994). Inhibitory control of neurodynamics: Opponent mechanisms in sequencing and selective attention. In M. Oaksford \& G. D. A. Brown (Eds.), Neurodynamics and psychology. London: Academic Press.

Houghton, G., \& Hartley, T. (1996). Parallel models of serial behaviour: Lashley revisited. Psyche, 2. Symposium on Implicit Learning [On-line]. Available: http://psyche.cs.monash.edu/

Houghton, G., \& Tipper, S. P. (1994). A model of inhibitory mechanisms in selective attention. In D. Dagenbach \& T. H. Carr (Eds.), Inhibitory processes in attention, memory, and language (pp. 53-112). San Diego: Academic Press.

Houghton, G., \& Tipper, S. P. (1996). Inhibitory mechanisms of neural and cognitive control: Applications to selective attention and sequential action. Brain \& Cognition, 30, 20-43.

houghton, G., Tipper, S. P., Weaver, B., \& Shore, D. I. (1996). Inhibition and interference in selective attention: Some tests of a neural network model. Visual Cognition, 3, 119-164.

JACOBY, L. L., \& Dallas, M. (1981). On the relationship between autobiographical memory and perceptual learning. Journal of Experimental Psychology: General, 110, 306-340.

Kahneman, D., Treisman, A., \& GibBs, B. J. (1992). The reviewing of object files: Object-specific integration of information. Cognitive Psychology, 24, 175-219.

KLEIN, R. M., \& TAYLOR, T. (1994). Categories of cognitive inhibition with reference to attention. In D. Dagenbach \& T. H. Carr (Eds.), Inhibitory processes in attention, memory, and language (pp. 113-150). San Diego: Academic Press.

LOGAN, G. D. (1988). Toward an instance theory of automatization. Psychological Review, 95, 492-527.

LowE, D. G. (1979). Strategies, context, and the mechanisms of response inhibition. Memory \& Cognition, 7, 382-389.

LowE, D. G. (1985). Further investigations of inhibitory mechanisms in attention. Memory \& Cognition, 13, 74-80.

Lupiáñez, J., Milán, E. G., Tornay, F. J., Madrid, E., \& Tudela, P. (1997). Does IOR occur in discrimination tasks? Yes, it does, but later. Perception \& Psychophysics, 59, 1241-1254.

LuPíñ̃EZ, J., \& MilLIKEN, B. (1999). Inhibition of return and the attentional set for integrating versus differentiating information. Journal of General Psychology, 126, 392-418.

May, C. P., Kane, M. J., \& Hasher, L. (1995). Determinants of negative priming. Psychological Bulletin, 118, 35-54.

MAYLOR, E. A. (1985). Facilitatory and inhibitory components of orienting in visual space. In M. I. Posner \& O. S. M. Marin (Eds.), $A t$ tention and performance $X I$ (pp. 189-204). Hillsdale, NJ: Erlbaum.

Milliken, B., \& JoORdENS, S. (1996). Negative priming without overt prime selection. Canadian Journal of Experimental Psychology, 50, 333-346.

Milliken, B., Joordens, S., Merikle, P., \& Seiffert, A. (1998). Selective attention: A re-evaluation of the implications of negative priming. Psychological Review, 105, 203-229.

Milliken, B., Tipper, S. P., \& WeAver, B. (1994). Negative priming in a spatial localization task: Feature mismatching and distractor inhibition. Journal of Experimental Psychology: Human Perception \& Performance, 20, 624-646.

Mondor, T. A., BreaU, L. M., \& Milliken, B. (1998). Inhibitory pro- 
cesses in auditory selective attention: Evidence of location-based and frequency-based inhibition of return. Perception \& Psychophysics, 60, 296-302.

Moore, C. M. (1994). Negative priming depends on probe-trial conflict: Where has all the inhibition gone? Perception \& Psychophysics, 56, 133-147.

NeILl, W. T., \& MATHIS, K. M. (1998). Transfer-inappropriate processing: Negative priming and related phenomena. In D. L. Medin (Ed.), The psychology of learning and motivation: Advances in research and theory (Vol. 38, pp. 1-44). San Diego: Academic Press.

NeILl, W. T., Terry, K. M., \& VAldes, L. A. (1994). Negative priming without probe selection. Psychonomic Bulletin \& Review, 1, 119-121.

Neill, W. T., Valdes, L. A., \& Terry, K. M. (1995). Selective attention and the inhibitory control of cognition. In F. N. Dempster \& C. J. Brainerd (Eds.), New perspectives on interference and inhibition in cognition (pp. 207-261). New York: Academic Press.

Neill, W. T., Valdes, L. A., Terry, K. M., \& Gorfein, D. S. (1992). The persistence of negative priming: II. Evidence for episodic trace retrieval. Journal of Experimental Psychology: Learning, Memory, \& Cognition, 18, 993-1000.

OrTells, J. J., \& Tudela, P. (1996). Positive and negative semantic priming of attended and unattended parafoveal words in a lexical decision task. Acta Psychologica, 94, 209-226.

PARK, J., \& KANWISHER, N. (1994). Negative priming for spatial location: Identity mismatching, not distractor inhibition. Journal of Experimental Psychology: Human Perception \& Performance, 20, 613-623.

POSNER, M. I., \& COHEN, Y. (1984). Components of visual orienting. In H. Houma \& D. G. Bouwhuis (Eds.), Attention and performance $X$ : Control of language processes (pp. 531-556). Hillsdale, NJ: Erlbaum.

Posner, M. I., Cohen, Y., Chonte, L. S., Hockey, R., \& Maylor, E. (1984). Sustained concentration: Passive filtering or active orienting. In S. Kornblum \& J. Requin (Eds.), Preparatory states and processes (pp. 49-65). Hillsdale, NJ: Erlbaum.

Posner, M. I., Rafal, R. D., Choate, L. S., \& Vaughan, J. (1985). Inhibition of return: Neural basis and function. Cognitive Neuropsychol$o g y, 2,211-228$.

PotTer, M. C. (1993). Very short-term conceptual memory. Memory \& Cognition, 21, 156-161.

PratT, J. (1995). Inhibition of return in a discrimination task. Psychonomic Bulletin \& Review, 2, 117-120.

Pratt, J., \& Abrams, R. A. (1999). Inhibition of return in discrimination tasks. Journal of Experimental Psychology: Human Perception \& Performance, 25, 229-242.

Rafal, R. D., Calabresi, P., Brennan, C., \& Sciolto, T. (1989). Saccade preparation inhibits reorienting to recently attended locations. Journal of Experimental Psychology: Human Perception \& Performance, 15, 673-685.

RATCLIF, R., \& MCKoon, G. (1988). A retrieval theory of priming in memory. Psychological Review, 95, 385-408.

Raymond, J. E., Shapiro, K. L., \& Arnell, K. M. (1992). Temporary suppression of visual processing in an RSVP task: An attentional blink? Journal of Experimental Psychology: Human Perception \& Performance, 18, 849-860.

Reuter-Lorenz, P. A., JHA, A. P., \& Rosenquist, J. N. (1996). What is inhibited in inhibition of return? Journal of Experimental Psychology: Human Perception \& Performance, 22, 367-378.

Scarborough, D. L., Cortese, D., \& Scarborough, H. S. (1977). Frequency and repetition effects in lexical memory. Journal of Experimental Psychology: Human Perception \& Performance, 3, 1-17.

Shapiro, K. L., \& Loughlin, C. (1993). The locus of inhibition in the priming of static objects: Object token versus location. Journal of Experimental Psychology: Human Perception \& Performance, 19, 352363.

Shimojo, S., Tanaka, Y., Hikosaka, O., \& Miyauchi, S. (1996). Vision, attention, and action: Inhibition and facilitation revealed by reaction time and the line motion. In T. Inni \& J. L. McClelland (Eds.), Attention and performance XVI: Information integration in perception and communication (pp. 15-46). Cambridge, MA: MIT Press, Bradford Books.

STROOP, J. R. (1935). Studies of interference in serial verbal reactions. Journal of Experimental Psychology, 18, 643-662.
Stuss, D. T., Toth, J. P., Franchi, D., Alexander, M. P., Tipper, S. P., \& CraIK, F. I. M. (1999). Dissociation of attentional processes in patients with focal frontal and posterior lesions. Neuropsychologia, 37, 1005-1027.

TENPENNy, P. L. (1995). Abstractionist versus episodic theories of repetition priming and word identification. Psychonomic Bulletin \& Review, 2, 339-363.

Terry, K. M., Valdes, L. A., \& Neill, W. T. (1994). Does "inhibition of return" occur in discrimination tasks? Perception \& Psychophysics, 55, 279-286.

TIPPER, S. P. (1985). The negative priming effect: Inhibitory effects of ignored primes. Quarterly Journal of Experimental Psychology, 37A, $571-590$.

Tipper, S. P., Bourque, T., Anderson, S., \& Brehaut, J. C. (1989). Mechanisms of attention: A developmental study. Journal of Experimental Child Psychology, 48, 353-378.

Tipper, S. P., Brehaut, J. C., \& Driver, J. (1990). Selection of moving and static objects for the control of spatially directed action. Journal of Experimental Psychology: Human Perception \& Performance, 16, 492-504.

TIPPER, S. P., \& Cranston, M. (1985). Selective attention and priming: Inhibitory and facilitatory effects of ignored primes. Quarterly Journal of Experimental Psychology, 37A, 591-611.

TiPPER, S. P., Driver, J., \& Weaver, B. (1991). Object-centered inhibition of return of visual attention. Quarterly Journal of Experimental Psychology, 43A, 289-298.

Tipper, S. P., Weaver, B., \& Houghton, G. (1994). Behavioral goals determine excitation-inhibition states of the internal representations of unattended objects. Quarterly Journal of Experimental Psychology, 47A, 809-840.

Tipper, S. P., Weaver, B., \& Milliken, B. (1995). Spatial negative priming without mismatching: Comment on Park and Kanwisher. Journal of Experimental Psychology: Human Perception \& Performance, 21, 1220-1229.

VAN Selst, M. A., \& Jolicoeur, P. (1994). A solution to the effect of sample size on outlier elimination. Quarterly Journal of Experimental Psychology, 47A, 631-650.

Weichselgartner, E., \& Sperling, G. (1988). Dynamics of automatic and controlled visual attention. Science, 238, 778-780.

WhITTLESEA, B. W. A., \& JACOBY, L. L. (1990). Interaction of prime repetition with visual degradation: Is priming a retrieval phenomenon? Journal of Memory \& Language, 29, 546-565.

YANTIS, S., \& JONIDES, J. (1984). Abrupt visual onsets and selective attention: Evidence from visual search. Journal of Experimental Psychology: Human Perception \& Performance, 10, 601-621.

YANTIS, S., \& JONIDES, J. (1990). Abrupt visual onsets and selective attention: Voluntary versus automatic allocation. Journal of Experimental Psychology: Human Perception \& Performance, 16, 12 l-134.

\section{NOTES}

1. Our primary concern was to ensure that the prime stimulus did not carry any predictive information regarding the location of the subsequent probe target. Indeed, the designs of all of the experiments reported in this article satisfied this constraint. For example, in Experiment 1 , two primes were used, and the probe target was equally likely to appear in the attended prime location, the ignored prime location, or either of the unoccupied prime locations. However, because there were no distractor-location-repeated trials in Experiment 1, whenever a probe item appeared in an occupied prime location, it was the probe target. As a result, the participants could have selected the probe target on locationrepeated trials on the basis of which of two probes appeared in a previously occupied location, rather than on the basis of which of two probes matched the color of the central cue (we thank John Christie for pointing this out). Although this is a theoretical possibility, we have rejected this strategy as the basis for the different results in Experiment 1 and Experiments 2,3A, and 3B (in which distractor-location-repeated trials were presented) for the following reason. Note that the critical result in Experiment 1 was that the participants were slower to respond to location-repeated trials than to location-changed trials. If location repetition itself had served as a selection cue and if this cue were easier to use 
than the central color cue, one would expect location-repeated trials to have been responded to more quickly than location-changed trials. This was not the case for either color-repeated or color-changed trials in this experiment. Furthermore, it is difficult to reconcile use of this strategy with the color repetition effect found in this experiment, but not in subsequent experiments that did contain distractor repetition trials.

2. The confound inherent to the comparison presented here is slightly different from that in the $\mathrm{X}-\mathrm{O}$ spatial localization procedure. In the $\mathrm{X}-\mathrm{O}$ spatial localization procedure, the symbol used for targets appears on ignored repetition, attended repetition, and control trials. The confound occurs because the correspondence between symbols at the probe target location differs for ignored and attended repetition conditions. In the contrast presented here, the color used to select a target is repeated for the location-repeated condition, but not for the location-changed condition. Although the precise confound differs between these two comparisons, the general point is that not attending to confounds related to the stimulus dimension used to define the target can give the appearance of different location repetition effects for attended and ignored primes.

3. The ANOVA for the distractor-location-repeated conditions was slightly different from that for the distractor-changed conditions. Note that for the distractor-location-repeated conditions, the difference between location-changed/color-changed and location-changed/colorrepeated conditions concerned the color match of both the target and the distractor with that of the prime items. In the analysis of distractorlocation-changed conditions, location-changed/color-changed and location-changed/color-repeated conditions differ only with respect to the color match of the probe target with the prime items.

4. A further experiment was conducted that reduced the number of potential locations at which targets could appear from four to two. This experiment was conducted to determine whether the effects reported here occur only when the probe is more likely to occur at a not-repeated location than at a repeated location. Whereas in Experiment $3 \mathrm{~A}$ four locations were used and the proportion of repetitions was .25, in this experiment two locations were used, and the proportion of repetitions was .50. Once again, mean RTs were slower in the repeated condition $(473 \mathrm{msec})$ than in the control condition [ $440 \mathrm{msec} ; t(7)=3.04, p<.02$ ]

5 . It should be noted that this account of inhibition of return replaces a slightly different explanation originally put forward in Houghton and Tipper (1994).

6. Similar logic might be used to explain why inhibition of return often emerges at longer SOAs in discrimination tasks involving identity or color than in detection tasks (Lupiáñez et al., 1997; Lupiáñez \& Milliken, 1999).

7. Some recent findings indicate that left and right frontal lesions may differentially affect spatial negative priming and inhibition of return (Stuss et al., 1999). This result appears to contradict our proposal that inhibition of return and spatial negative priming are determined by similar processes. However, spatial negative priming and inhibition of return may be expected to tap similar neural sites only when the tasks used to measure them are similar at a process level, as in the present study. When the tasks are different at a process level, the processes that underlie spatial negative priming and inhibition of return may well also differ. Thus, from an inhibitory process perspective, just as lateral inhibition operates in many different neural sites, inhibitory processes in separate neural sites could be responsible for negative priming and inhibition of return. Similarly, from a constructive retrieval perspective, both negative priming and inhibition of return are emergent consequences of automatic integrative processes that could conceivably take place at any neural site.

\begin{tabular}{|c|c|c|c|c|}
\hline \multicolumn{5}{|c|}{$\begin{array}{l}\text { APPENDIX } \\
\text { The Number of Trials per Condition } \\
\text { Within a Block in Experiments 1, 2, and 3B }\end{array}$} \\
\hline \multicolumn{5}{|c|}{ Experiment 1} \\
\hline & \multicolumn{4}{|c|}{ Attended/Ignored Repetition } \\
\hline & \multicolumn{2}{|c|}{ Attended } & \multicolumn{2}{|c|}{ Ignored } \\
\hline Location & $\begin{array}{c}\text { Color } \\
\text { Changed }\end{array}$ & $\begin{array}{c}\text { Color } \\
\text { Repeated }\end{array}$ & $\begin{array}{c}\text { Color } \\
\text { Changed }\end{array}$ & $\begin{array}{c}\text { Color } \\
\text { Repeated }\end{array}$ \\
\hline Changed & 1 & 2 & 1 & 2 \\
\hline Repeated & 2 & 1 & 2 & 1 \\
\hline
\end{tabular}

Experiment 2

\begin{tabular}{|c|c|c|c|c|}
\hline \multirow[b]{3}{*}{ Location } & \multicolumn{4}{|c|}{ Distractor Location } \\
\hline & \multicolumn{2}{|c|}{ Changed } & \multicolumn{2}{|c|}{ Repeated } \\
\hline & $\begin{array}{c}\text { Color } \\
\text { Changed }\end{array}$ & $\begin{array}{c}\text { Color } \\
\text { Repeated }\end{array}$ & $\begin{array}{l}\text { Color } \\
\text { Changed }\end{array}$ & $\begin{array}{c}\text { Color } \\
\text { Repeated }\end{array}$ \\
\hline hange & 1 & 1 & 2 & 2 \\
\hline Repeated & 2 & 2 & 1 & 1 \\
\hline
\end{tabular}

Experiment 3B

\begin{tabular}{cccc} 
& \multicolumn{2}{c}{ Color } & \\
\cline { 2 - 3 } Location & Changed & Repeated & DR \\
\hline Changed & 3 & 3 & 3 \\
Repeated & 2 & 1 & \\
\hline
\end{tabular}

Note-DR, distractor location repeated.

(Manuscript received March 11, 1999; revision accepted for publication November 15, 1999.) 